\title{
Predictive Value of RNA Protein Kinase and Interferon- $\gamma$ for HCV Clearance in Patients with Hepatitis C
}

\author{
Yuanjiang Liu \\ Mingzhi Medical Science Examination Laboratory, Wuhan 430074, Hubei, China \\ Email: 3348069375@qq.com
}

\begin{abstract}
Objective - To analyze and study the predict value of serum levels of RNA-dependent protein kinase (PKR), tumor necrosis factor alpha (TNF- $\alpha$ ), interleukin 10 (IL-10) and interferon gamma (INF- $\gamma$ ) for HCV clearance in patients with HCV infection. Methods - A total of 92 patients with chronic HCV infection (case group), 33 patients with HCV spontaneous resolvers (SR group) and 100 healthy persons (control group) during the same period from January 2018 to October 2019 in our hospital's infection department were collected as the study Object. The basic data and routine biochemical indicators of the three groups of subjects were detected and compared, and the levels of serum PKR, TNF- $\alpha$, INF- $\gamma$ and IL-10 were detected by enzyme-linked immunosorbent assay. The ROC work curve analysis was used to evaluate the predictive value of the above immune indicators for HCV clearance in patients with hepatitis C. Results - Compared with the control group and the case group, the serum PKR, TNF- $\alpha$ and IFN- $\gamma$ levels in the SR group increased, while the IL-10 levels decreased, the difference was statistically significant. Predictive analysis of HCV clearance in chronic hepatitis $\mathrm{C}$ patients found that the area under the ROC curve of PKR and IFN- $\gamma$ were 0.784 (95\% CI: 0.704-0.864, P <0.001) and $0.645(95 \% \mathrm{CI}: 0.538-0.751, \mathrm{P}=0.014)$, and the optimal cut-off points are $7.00 \mathrm{ng} / \mathrm{mL}$ and $101.00 \mathrm{pg} / \mathrm{mL}$, respectively. Conclusion - Both PKR and IFN- $\gamma$ have a certain predictive value for the clearance of HCV in patients with chronic hepatitis $\mathrm{C}$, which can be used as a potential biomarker for predicting the outcome of HCV infection.
\end{abstract}

Keywords: RNA protein kinase, hepatitis C virus, virus clearance, predictor

\section{Introduction}

Hepatitis $\mathrm{C}$ refers to the liver infection caused by the hepatitis $\mathrm{C}$ Virus (HCV), which is generally transmitted through blood or body fluids. It is estimated that about 170 million people worldwide are infected with $\mathrm{HCV}^{[1]}$. For a small number of patients, they are able to resist the infection as they were infected with HCV and HCV is generally cleared spontaneously within the first 6 months after infection, and such patients are referred to as HCV spontaneous resolvers (SRs) ${ }^{[2]}$. It has been reported that during the course of $\mathrm{HCV}$ infection, about $50-80 \%$ of patients developed into chronic hepatitis $\mathrm{C}$ patients, and spontaneous clearance of HCV without treatment occurred in about $15-30 \%$ of patients ${ }^{[3]}$. HCV spontaneous clearance can be occurred in patients with chronic HCV infection for many years ${ }^{[2]}$, which was often ignored in clinical diagnosis and treatment. Patients with chronic hepatitis $\mathrm{C}$, on most occasion, failed to show obvious clinical symptoms until it caused serious related complications that can lead to serious health problems such as liver fibrosis, cirrhosis, and even liver cancer. Patients with chronic hepatitis $\mathrm{C}$ were usually treated with a combination of interferon and antiviral drugs, and no HCV-RNA is detected within 6 months after the cessation of antiviral therapy ${ }^{[4]}$, which was rendered as healing. To avoid unnecessary antiviral based therapy, it is significant to identify individuals, among which HCV infection can be cleared spontaneously in patients with chronic hepatitis $\mathrm{C}$. It has been reported that RNA-dependent protein kinases (PKR), tumor necrosis factor $\alpha(\mathrm{TNF}-\alpha)$, Interferon-10 (IL-10) and interferon- $\gamma(\mathrm{INF}-\gamma)$ play an important role in the clearance of HCV in SR patients ${ }^{[5-9]}$, but the conclusions were inconsistent and controversial, and few studies were conducted to assess the levels of PKR, TNF- $\alpha$, IL-10 and INF- $\gamma$ in Chinese patients with chronic hepatitis C. Based on this, in this study, we analyzed the serum levels of the above four immune indicators in patients with chronic hepatitis $\mathrm{C}$ in China to explore the possibility of the use as biomarkers for predicting the prognosis of $\mathrm{HCV}$ infection.

\section{Data and methods}

\subsection{Study objects}

92 cases of chronic HCV infected persons (case group), 33 cases of HCV spontaneous resolvers (SR group, which was difficult to collect a large number of subjects) and 100 cases of healthy physical examination subjects (control group) 
in our laboratory from January 2018 to October 2019 were selected as the research subjects, ranging in age from 17 to 65. Inclusion criteria: (1) The diagnosis for patients with chronic HCV met the diagnostic criteria of the Prevention and Treatment Guidelines for Hepatitis C (2019 Edition) issued by the Chinese Society of Liver Diseases and the Chinese Society of Infectious Diseases ${ }^{[10]}$, and the patients were HCV-RNA positive for more than 6 months and anti-HCV antibodies were positive; (2) Spontaneous resolvers with HCV were diagnosed negative for HCV-RNA and positive for anti-HCV antibodies within 6 months after initial diagnosis of $\mathrm{HCV}$ infection, who failed to receive any treatment for hepatitis C; (3) Those with general good physical condition and were willing to participate in the study. Exclusion criteria: (1) Patients with hepatitis B virus or other hepatitis virus infection; (2) Patients with other liver diseases (such as autoimmune hepatitis, fatty liver, alcoholic liver, cirrhosis, liver cancer, etc.) or who are receiving hepatotoxic drug therapy; (3) Patients who were in pregnancy or with thyroid dysfunction, malignant tumor, heart disease and other major diseases after receiving transplant. This study was in line with the Code of Practice of the World Medical Association (Declaration of Helsinki).This research scheme had been reviewed and approved by the Ethics Committee of Wuhan Mingzhi Medical Laboratory.

\subsection{Research Methods}

(1) Basic information: Detailed clinical and pathological data of patients, including demographic data, family history of liver disease, smoking history and alcohol consumption history, were obtained through the electronic medical record system. (2) Biochemical indicators: Siemens large-scale automatic biochemical testing instruments and their supporting reagents were used by skilled laboratory technicians to detect the liver function related indicators of the research objects according to the standard operating steps in the instructions. The testing indexes included: Enzymological examination (ALT, AST, GGT, ALP); Protein tests (albumin (AIB), globulin (GLB)) and bilirubin tests (total bilirubin (TBil) and direct bilirubin (DBil)). (3): The serum PKR level of the subjects was detected by using the ELISA kit produced by Shanghai Xinyu Biotechnology Co., Ltd. (Article No. : XYEA520Hu;Testing area: 0.156-10 ng/mL;Sensitivity: $0.063 \mathrm{ng} / \mathrm{mL}$ ) and tumor necrosis factor $\alpha$ (TNF- $\alpha$, article No.: ZK-H064; Detection range: 1-300 pg/mL; Sensitivity: 1.0 pg/mL). Human interleukin-10 (IL-10, item number: D1000B; Detection range: 7.8-500 pg/mL; Sensitivity: $3.9 \mathrm{pg} / \mathrm{mL}$ ) and human interferon $\gamma$ (IFN- $\gamma$, Item No.: DIF50C; Detection range: 15.6-1,000 pg/mL; Sensitivity: $8 \mathrm{pg} / \mathrm{mL}$ ). All operations were strictly in accordance with the manufacturer's instructions.

\subsection{Statistical methods}

In statistical analysis, continuous variables and classified variables were expressed as mean \pm , standard error $( \pm \mathrm{s})$ and number of cases/percentage ( $\mathrm{n}, \%$ ) respectively. In the comparative analysis of variables, continuous variables and classified variables were analyzed by independent sample $t$ test /ANOVA test and chi-square test respectively. The predictive value of serum immune indexes in HCV clearance in chronic HCV infected patients was evaluated by ROC curve analysis. All statistical tests were bilateral, and $\mathrm{P}<0.05$ was considered statistically significant. All data analysis was performed using IBM SPSS statistical software (Version 20).

\section{Results}

\subsection{Comparison of general data}

The clinical and biochemical characteristics of the study population were shown in Table 1. The basic data of case group, SR group and control group demonstrated little difference with comparability. In the case group, HCV genotype 1B accounted for $56.52 \%$ (52/92), and HCV genotype $2 \mathrm{~A}$ accounted for $35.87 \%$ (33/92).

Patients with HCV genotype $1 \mathrm{~b} / 2 \mathrm{a}$ accounted for $2.17 \%$ (2/92); there were 5 patients with ungenotyped $\mathrm{HCV}(5.43 \%)$. There were significant differences in ALT, AST, GGT, ALP, TBIL and DBIL levels among the three groups $(\mathrm{P}<0.05)$. On the other hand, serum ALB levels were significantly lower in the case group than in the control and SR groups.

Table 1. Comparison of general data of control group, SR group and case group

\begin{tabular}{|c|c|c|c|c|c|}
\hline Variable study & $\begin{array}{l}\text { Control group } \\
\quad(n=100)\end{array}$ & $\begin{array}{l}\text { SR group } \\
(\mathrm{n}=33)\end{array}$ & $\begin{array}{l}\text { Case group } \\
(\mathrm{n}=92)\end{array}$ & $\mathrm{F} / \mathrm{t} / x^{2}$ value & $P$ value \\
\hline Age(years old) & $50.93 \pm 13.67$ & $49.11 \pm 11.56$ & $52.81 \pm 13.56$ & 0.789 & 0.733 \\
\hline Male & $58(58 \% .00)$ & $21(63.64 \%)$ & $56(60.87 \%)$ & 1.458 & 0.316 \\
\hline Weight(kg) & $68.52 \pm 8.28$ & $67.23 \pm 7.92$ & $66.03 \pm 7.84$ & 0.832 & 0.435 \\
\hline BMI & $23.63 \pm 3.65$ & $23.82 \pm 4.12$ & $22.13 \pm 4.68$ & 0.815 & 0.473 \\
\hline Family history of liver disease & $7(7.00 \%)$ & $3(9.09 \%)$ & $11(11.96 \%)$ & 0.515 & 0.066 \\
\hline
\end{tabular}




\begin{tabular}{cccccc}
\hline Variable study & $\begin{array}{c}\text { Control group } \\
(\mathrm{n}=100)\end{array}$ & $\begin{array}{c}\text { SR group } \\
(\mathrm{n}=33)\end{array}$ & $\begin{array}{c}\text { Case group } \\
(\mathrm{n}=92)\end{array}$ & F/t $/ x^{2}$ value & $P$ value \\
\hline Excessive drinking( ${ }^{3} 10$ years $)$ & $4(4.00 \%)$ & $1(3.03 \%)$ & $4(4.35 \%)$ & 3.347 & 0.257 \\
Smoking(310 years) & $8(8.00 \%)$ & $2(6.07 \%)$ & $7(7.61 \%)$ & 3.183 & 0.281 \\
ALT(U/L) & $17.53 \pm 4.71$ & $36.09 \pm 7.68^{\mathrm{a}}$ & $47.29 \pm 9.28^{\mathrm{ab}}$ & 11.525 & $<0.001$ \\
AST(U/L) & $16.60 \pm 2.48$ & $45.56 \pm 10.52^{\mathrm{a}}$ & $59.48 \pm 9.27^{\mathrm{ab}}$ & 9.107 & $<0.001$ \\
GGT(U/L) & $19.67 \pm 8.67$ & $28.67 \pm 8.26^{\mathrm{a}}$ & $48.67 \pm 8.92^{\mathrm{ab}}$ & 9.853 & $<0.001$ \\
ALP(U/L) & $58.48 \pm 8.11$ & $65.48 \pm 7.42^{\mathrm{a}}$ & $88.82 \pm 9.53^{\mathrm{ab}}$ & 9.692 & $<0.001$ \\
AIB(g/L) & $37.34 \pm 4.11$ & $36.98 \pm 5.68$ & $27.34 \pm 5.95^{\mathrm{ab}}$ & 10.914 & $<0.001$ \\
GLB(g/L) & $26.60 \pm 3.48$ & $28.56 \pm 3.52$ & $31.60 \pm 3.48^{\mathrm{a}}$ & 0.824 & 0.329 \\
TBIL $(\mu \mathrm{mol} / \mathrm{L})$ & $6.60 \pm 2.81$ & $8.56 \pm 3.12^{\mathrm{a}}$ & $13.48 \pm 3.74^{\mathrm{ab}}$ & 11.801 & $<0.001$ \\
DBIL $(\mu \mathrm{mol} / \mathrm{L})$ & $1.34 \pm 0.76$ & $3.21 \pm 1.06^{\mathrm{a}}$ & $8.25 \pm 1.12^{\mathrm{ab}}$ & 11.693 & $<0.001$ \\
\hline
\end{tabular}

Note: a, $\mathrm{P}<0.05$ after compared with the control group; $\mathrm{b}, \mathrm{P}<0.05$ after compared with SR group; *, $\mathrm{P}<0.05$, which was statistically significant.

\subsection{Changes in the level of immune indexes in patients with hepatitis $\mathbf{C}$}

The serum levels of PKR, TNF- $\alpha$, IL-10 and IFN- $\gamma$ in the three groups were shown in Figure 1 below. The levels of serum PKR, TNF- $\alpha$ and IFN- $\gamma$ in SR group were higher than those in control group and case group, and the difference was statistically significant $(\mathrm{P}<0.05)$. The level of serum IL-10 in SR group was higher than that in control group and lower than that in case group, with statistical significance $(\mathrm{P}<0.05)$. The levels of serum PKR, TNF- $\alpha$ and INF- $\gamma$ in case group were significantly higher than those in control group, but lower than those in SR group, with statistical significance $(\mathrm{P}<0.05)$.
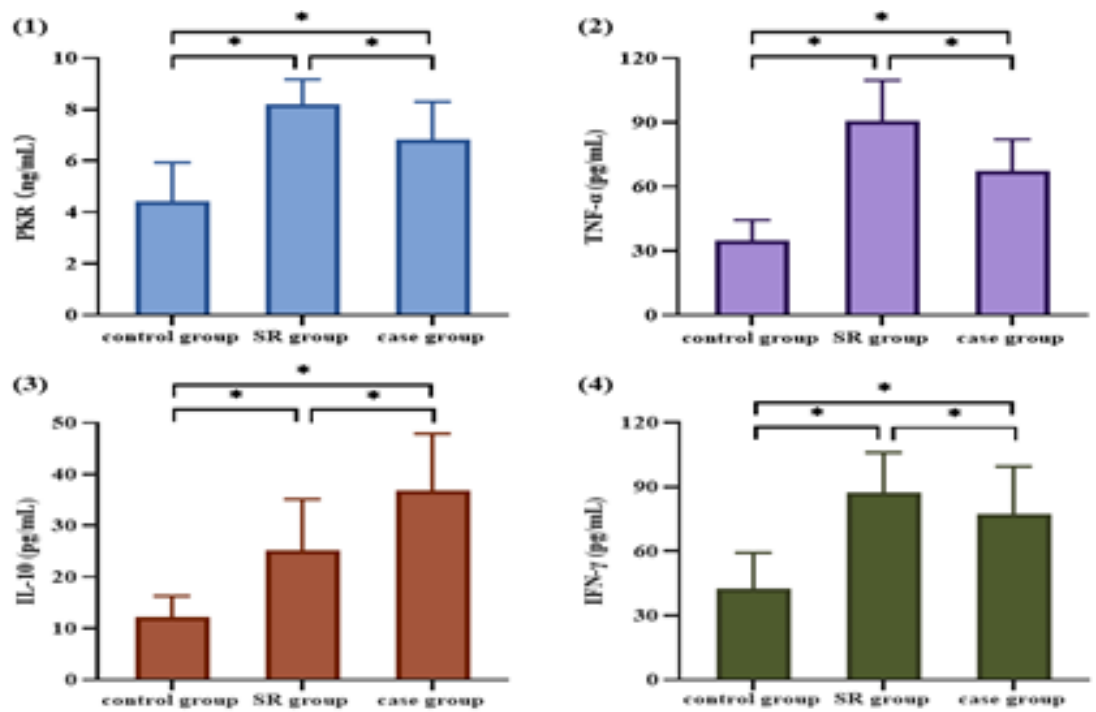

Figure 1. Changes of immune indexes in control group, SR group and case group

Note: The immune indexes of the control group, SR group and case group were as follows: (1) PKR: $(4.43 \pm 1.51) \mathrm{ng} / \mathrm{mL},(8.20 \pm 0.98) \mathrm{ng} / \mathrm{mL}$, (6.83 \pm 1.41$) \mathrm{ng} / \mathrm{mL}$; (2)TNF- $\alpha$ : (34.75 \pm 9.67$) \mathrm{pg} / \mathrm{mL},(90.60 \pm 19.16) \mathrm{pg} / \mathrm{mL},(67.29 \pm 14.85) \mathrm{pg} / \mathrm{mL}$; (3) IL-10: (12.28 \pm 4.04$) \mathrm{pg} / \mathrm{mL},(25.17 \pm 9.99) \mathrm{pg} /$

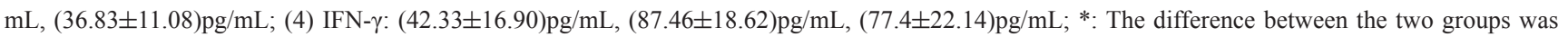
statistically significant $(\mathrm{P}<0.05)$.

\subsection{ROC curve analysis of the predictive value of immune indexes in $\mathrm{HCV}$ clearance in patients with chronic hepatitis $\mathrm{C}$}

Figure 1 shows the ROC curve analysis results of the predictive value of immune indexes in $\mathrm{HCV}$ clearance in patients with hepatitis C (relative to SR). The areas under ROC curves of PKR, TNF- $\alpha$, IL-10 and IFN- $\gamma$ were 0.784 (95\%CI: 0.7040.864, P<0.001), 0.160 (95\%CI: $0.087-0.234, \mathrm{P}<0.001), 0.221$ (95\%CI: $0.132-0.310, \mathrm{P}<0.001), 0.645$ (95\%CI: 0.538 - 
$0.751, \mathrm{P}=0.014)$ respectively. The results showed that both PKR and IFN- $\gamma$ had a certain predictive value for HCV clearance in patients with hepatitis $\mathrm{C}$, and PKR had a better predictive value. The optimal cut point of PKR was $7.00 \mathrm{ng} / \mathrm{mL}$. When PKR > was $7.00 \mathrm{ng} / \mathrm{mL}$, the possibility of HCV clearance in patients with hepatitis C increased by 9.505 times. When serum PKR was $7.00 \mathrm{ng} / \mathrm{mL}$, the sensitivity, specificity and Youden index were $93.94 \%, 57.61 \%$ and 0.5155 respectively. The optimal cut point of IFN- $\gamma$ was $101.00 \mathrm{pg} / \mathrm{mL}$. When serum IFN- $\gamma>101.00 \mathrm{pg} / \mathrm{mL}$, the probability of HCV clearance in patients with hepatitis C was 1.436 times higher.The sensitivity, specificity and Youden index were $87.00 \%, 39.39 \%$ and 0.2639 when the serum IFN- $\gamma$ cut-off point was $101.00 \mathrm{pg} / \mathrm{mL}$.

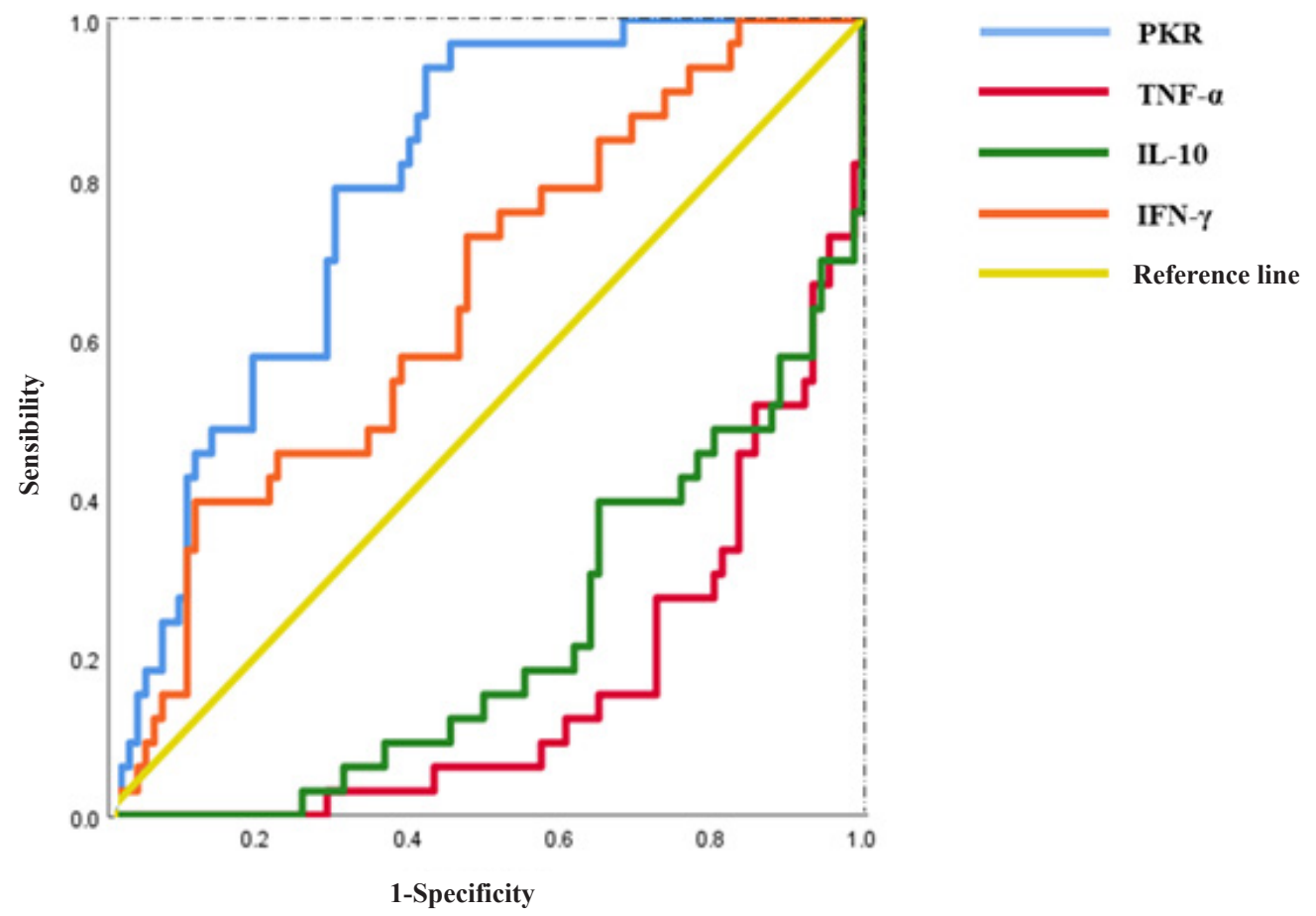

Figure 1. ROC curve analysis of the predictive value of four immune indexes for HCV clearance in patients with hepatitis C

\section{Discussion}

$\mathrm{HCV}$ is an enveloped-RNA virus belonging to the Flaviviidae family. It is estimated that about $3 \%$ of the world's population were infected with $\mathrm{HCV}$ and were at risk of developing chronic liver disease ${ }^{[11]}$. Most HCV could successfully elude detection by the body's immune system, thus establishing a permanent infection in the body. Up to $80 \%$ of people infected with HCV developed persistent viremia that can lead to cirrhosis, liver failure, and hepatocellular carcinoma ${ }^{[1]}$. However, a small number of SR patients were able to remove HCV from the body spontaneously after the acute HCV infection phase without treatment, and the clearance rate of spontaneous virus was reported to be about $15-30 \%{ }^{[3]}$. At present, the exact mechanism of HCV clearance in SR patients remained unclear. A large number of literature have shown that changes in cytokines/enzymes involved in HCV-specific cellular immunity and immune response may contribute to spontaneous clearance of $\mathrm{HCV}$ in patients ${ }^{[5-9]}$. Therefore, to predict the outcome of HCV infection by identifying detectable biomarkers is of great value for HCV prevention and control.

TNF- $\alpha$ and IFN- $\gamma$ are important pro-inflammatory cytokines that play a key role in the development of human immune respons $^{[12]}$. TNF- $\alpha$ is believed to be a pro-inflammatory cytokine involved in innate immune response, and its main biological role is to defend against bacterial, viral and parasitic infections ${ }^{[6]}$. TNF- $\alpha$ plays a key role in the induction of acute liver response and fever, and up-regulates host defense in a variety of ways ${ }^{[6]}$. IFN- $\gamma$ is produced mainly by activated $\mathrm{T}$ lymphocytes and natural killer cells and is significantly increased in the immune response of cellular immunity ${ }^{[7]}$. IFN- $\gamma$ is endowed with antiviral activity and can regulate macrophages, T/B lymphocytes and granulocytes ${ }^{[13]}$. In this study, we found that serum levels of TNF- $\alpha$ and IFN- $\gamma$ were significantly increased in the SR group compared with those in patients with chronic hepatitis $\mathrm{C}$.

Therefore, TNF- $\alpha$ and IFN- $\gamma$ may play a role in the immune response to eliminate the virus. At the same time, IFN- $\gamma$ also has a certain predictive value for HCV clearance in chronic infected patients. When the serum IFN- $\gamma>101.00 \mathrm{pg} / \mathrm{mL}$ 
in patients with hepatitis $\mathrm{C}$, the possibility of $\mathrm{HCV}$ clearance in patients with hepatitis $\mathrm{C}$ increased by 1.436 times. IL-10 is an important immunomodulatory cytokine, which can inhibit innate and adaptive immunity ${ }^{[14]}$. In this study, the serum IL-10 level of patients with chronic hepatitis $\mathrm{C}$ was significantly higher than that of patients with SR, which confirmed the role of IL-10 in inhibiting the immune response and the decrease of IL-10 expression level may contribute to the spontaneous clearance of HCV. PKR is encoded by the EIF2AK2 gene, which is a double-stranded RNA-dependent serine/threonine protein kinase induced by interferon $\operatorname{IFN}^{[15]}$.

As a major mediator of antiviral replication and pathogenesis of IFN, PKR can promote innate immune response to viral infection ${ }^{[15]}$. It has been demonstrated that PKR can be activated by HCV infection and HCV is capable of inhibiting the expression of IFN and IFN-stimulated genes by controlling the translation of transcriptional mRNA ${ }^{[16]}$. HCV also induces phosphorylation of PKR and eIF2 $\alpha$, inhibiting the translational expression of major histocompatibility complex I, and thus establishing a chronic infection state in the body ${ }^{[16]}$. During HCV infection, IFN induced the expression of PKR (increased by 5-10 times), which stimulated the phosphorylation of serine 51 on the $\alpha$ subunit (eIF2 $\alpha$ ) of protein synthesis initiation factor 2 in eukaryotic cells and prevented protein synthesis in infected cells ${ }^{[16]}$. In this study, PKR serum levels were significantly increased in the SR group compared with patients with chronic hepatitis C. These results suggest that PKR plays a critical role in HCV clearance and that PKR may be a potential biomarker for HCV clearance in patients with chronic hepatitis C. Through ROC curve analysis, we found that PKR has a good predictive value for HCV clearance in chronic HCV infected patients. The optimal cut-point for PKR to predict HCV clearance was $7.00 \mathrm{ng} / \mathrm{mL}$. When PKR $>7.00 \mathrm{ng} / \mathrm{mL}$, the likelihood of HCV clearance was 9.505 times higher.

In conclusion, the following conclusions can be drawn from this study. (1) Compared with chronic HCV infected patients, serum PKR, TNF- $\alpha$ and IFN- $\gamma$ levels of SR were increased, and IL-10 levels were decreased. (2) PKR and IFN- $\gamma$ had good predictive value for HCV clearance in chronic HCV infected patients, and the best cut point was $7.00 \mathrm{ng} / \mathrm{mL}$ and $101.00 \mathrm{pg} / \mathrm{mL}$, respectively. PKR and IFN- $\gamma$ can be used as potential biomarkers to predict HCV infection outcome.

\section{References}

[1] Asselah T, Bourlière, Marc. Hepatitis C virus. Gastroenterology Clinics of North America. 2015; 44(4): 859-870.

[2] Cho Y K, Kim Y N, Song B C. Predictors of spontaneous viral clearance and outcomes of acute hepatitis C infection. Clinical and molecular hepatology. 2014; 20(4): 368-375.

[3] Merli M, Galli L, Poli A, et al. Rate and predictive factors of spontaneous hepatitis C virus clearance after acute infection in human immunodeficiency virus-positive subjects. Journal of Hepatology. 2017; 66(1): S278-S279.

[4] Wei Lai, Li Hong, Jia Jidong, et al. The role of direct antiviral drugs in the treatment of hepatitis C in China. Chinese Journal of Viral Diseases. 2017; 7(6): 405-407.

[5] Dina, El-Dahshan, Doaa, et al. Two novel SNPs in the promoter region of PKR gene in hepatitis C patients and their impact on disease outcome and response to treatment. Arab J Gastroenterol. 2018; 19(3): 106-115.

[6] Aldona, Kasprzak, Maciej, et al. Expression of cytokines (tnf- $\alpha$, il-1 $\alpha$, and il-2) in chronic hepatitis c: comparative hybridocytochemical and immunocytochemical study in children and adult patients. Journal of Histochemistry \& Cytochemistry. 2016; 52(1): 29-38.

[7] J.M. Pascasio, C. Vinaixa, M.T. Ferrer, et al. Fri-464-interferon-free antiviral therapy in cirrhotic patients infected with hepatitis c on the waiting list for liver transplantation. Journal of Hepatology. 2016; 64(2): S543-S545.

[8] Shen Hongyuan, Chen Yurong, Shen Jianlin. Hepatitis B Virus and Hepatitis C virus overinfection and its clinical significance. Chinese Journal of Nosocomiology. 2015; 2(13): 19-20+23.

[9] Xu Xiuwen, Li Ying, Tong Shaoyong, et al. The role of TNF- $\alpha$ and IL-2 gene promoter polymorphism in chronic hepatitis C virus infection in the host immune system. Journal of Guiyang Medical College. 2015; 3(6): 571-575.

[10] Wei Lai, Duan Zhongping, Wang Guiqiang. Guidelines for the prevention and treatment of hepatitis C (2019 Edition). Journal of Practical Hepatology. 2020; 23(01): 33-52.

[11] Tong Yemeng, Li Zhan, Cai Kun, et al. Research progress of drugs for hepatitis C. Chinese Journal of Pharmacoepidemiology. 2019; 2(7): 468-471.

[12] Nawaz R, Zahid S, Idrees M, et al. HCV-induced regulatory alterations of IL-1 $\beta$, IL-6, TNF- $\alpha$, and IFN- $\gamma$ operative, leading liver en-route to non-alcoholic steatohepatitis. Inflammation Research. 2017; 66(6): 477-486.

[13] Chen Zhiguang, Xue Jinqi, Fu Qin. The role of interferon- $\gamma$ in the immune system of bone. Chinese Journal of Osteoporosis. 2015; 2(3): 361-366.

[14] Yang Ruixue, Zhou Yaojia, He Wenlu, et al. Advances in the study of interleukin 10 (VIIL-10). Chinese Journal of Virology. 2018; 5(2): 161-166. 
[15] Wang Aihua, Guan Shihe, Yang Kai, et al. Interferon-induced double stranded RNA-dependent protein kinase (RNA-dependent protein kinase) in vitro against hepatitis B virus. Chinese Pharmacological Bulletin. 2015; 3(09): $75-79$.

[16] Suzuki R, Matsuda M, Shimoike T, et al. Activation of protein kinase R by hepatitis C virus RNA-dependent RNA polymerase. Virology. 2019; 3(529): 226-233 